\title{
28 Research Square \\ Relationship between dietary factors and recurrent aphthous stomatitis: A cross-sectional study
}

Kaiyuan Xu

Nanjing Stomatological Hospital https://orcid.org/0000-0001-5433-0652

Chongchong Zhou

nanjing stomatological hospital

Fan Huang

nanjing stomatological hospital

Ning Duan

Nanjing Stomatological Hospital

Yanyi Wang

nanjing stomatological hospital

Lichun Zheng

Nanjing Stomatological Hospital

Xiang Wang

Nanjing Stomatological Hospital

Wenmei Wang ( $\square$ wenmei-wang@hotmail.com )

nanjing stomatological hospital

\section{Research article}

Keywords: Recurrent aphthous stomatitis, Dietary habits, Cross-sectional study, Prevalence

Posted Date: October 13th, 2020

DOI: https://doi.org/10.21203/rs.3.rs-89917/v1

License: (c) (i) This work is licensed under a Creative Commons Attribution 4.0 International License.

Read Full License 


\section{Abstract}

Background: Recurrent aphthous stomatitis (RAS), a common oral mucosal disorder characterized by chronic, inflammatory, and ovoid ulcers, has a complex aetiology. The purpose of the study was to investigate the specific dietary factors influencing the prevalence of RAS.

Methods: A total of 754 participants aged 18 to 59 years in Nanjing were enrolled in this descriptive cross-sectional study. An anonymous questionnaire was adopted to investigate the distribution of RAS, dietary factors, self-reported trigger factors, and therapeutic methods.

Results: Among all participants, the prevalence rate of RAS was $21.4 \%$. The univariable analysis suggested fruits, dairy products, vegetables, and drinking water, but not fried foods, fermented foods, spicy foods, and eggs, as preventive factors of RAS. After adjusting for age and sex, multivariable regression analysis suggested fruits (adjusted odds ratio $[\mathrm{aOR}]=.430,95 \%$ confidence interval $[\mathrm{Cl}]=$ [.218-.847], $p=.015)$ and drinking water $(\mathrm{aOR}=.294,95 \% \mathrm{Cl}=[.119-.726], p=.008)$ as protective factors of RAS.

Conclusion: This study suggests that consumption of fruit and drinking water is negatively associated with RAS and dietary factors play an important role in RAS development. These results imply a potential adjunctive and complementary role of food in RAS treatment and some potential, simple, and feasible means for RAS prevention.

\section{Background}

Recurrent aphthous stomatitis (RAS), or recurrent oral ulceration (ROU), one of the most common oral mucosal disorders, affects $2 \% \sim 66 \%$ of the population according to worldwide epidemiological data [1]. Characterized by ovoid, small, multiple, and recurrent ulcers with circumscribed margins, yellow or grey floors, and erythematous haloes, and can greatly impact the function of eating, speaking, and swallowing in severe cases $[2,3]$.

To elucidate the pathogenesis of RAS, researchers have suggested many influence factors of RAS, including not only genetic factors, immune dysregulation, stress [3-6], but specific dietary factors [7-14]. It has been reported that cow's milk protein (CMP) in milk can induce RAS with an increase of anti-fresh cow's milk IgA, IgG, and IgE antibodies in serum [7, 8]. Moreover, other studies have suggested that some food, e.g., tomatoes, oranges, lemons, and pineapple can induce the pro-inflammatory cascade leading to RAS [11-13]. We designed this study to explore the potential associations between RAS and several dietary factors which are suggested as potential influence factors in literatures or in clinic $[7,14]$.

The cross-sectional survey aimed to collect data regarding RAS incidence, dietary factors, self-reported trigger factors and therapeutic methods to explore the relationships between RAS and dietary factors. This work has the potential to encourage further study of the aetiology of and prevention measures against RAS in the clinic. 


\section{Material And Methods}

\section{Sample size, study design, and participants}

A sample size of approximately 700 people was determined with the following formula:

$$
N=\frac{U_{\alpha}^{2} \times P_{0} \times\left(1-P_{0}\right)}{D^{2}} .
$$

in which $N$ represents the sample size, $U_{a}$ represents the Z-score for a given confidence interval $(\alpha=.05$, $\left.U_{a}=1.96\right), P_{0}$ represents the estimated prevalence $\left(P_{0}=20 \%\right),{ }^{7}$ and $D$ represents the permissible error $(D=$ $\left..15 \times P_{0}\right)$.

The cross-sectional study was conducted in Nanjing from June 2017 to September 2017 with a multistage random sampling method employed to randomly select 5 districts of Nanjing. Four neighbourhood communities were randomly chosen from each district. Forty civilians aged 18 to 59 years who had resided in Nanjing for at least 1 year were selected from each community. The exclusion criteria were mental/cognitive impairments, communication disabilities, and illiteracy.

An anonymous questionnaire was designed based on the previous studies with minor modifications to collect information, including demographic information, dietary factors, self-reported trigger factors, and therapeutic methods, during a face-to-face interview [15-21]. According to the description of Dietary Guidelines for Chinese Residents [22], daily consumptions of fruit, dairy, drinking water, and vegetable were estimated and classified into different levels; Consumption frequencies of other dietary factors were classified into three categories: often (at least 4 times per week), sometimes (1-3 times per week), never or seldom; Consumption frequencies of egg were classified into sometimes or often (at least 1 times per week), never or seldom. In line with the descriptions of the Dietary Guidelines for Chinese Residents [22], fruit included drupe, berry, melon, pome, citrus fruit; Dairy included skim/low-fat and whole milk, condensed milk, milk powder, milk tablets, liquid yogurt, curd yogurt, ice-cream, cheese, and butter; Drinking water included plain drinking water (bottled water and tap water) and beverages (soft drinks, energy drinks, alcoholic drinks, milk, coffee, juice, tea, and other beverage drinks), but not moisture of food; Vegetable included Cruciferae, Umbelliferae, Leguminosae, Solanum, Chenopodiaceae, and Cucurbitaceae. Participants who did not complete all questions on the questionnaire were excluded.

\section{Case definition}

According to the criteria suggested by S. S. Natah [23], we applied a set of diagnostic criteria (Table 1, Table 2) for RAS to distinguish it from other diseases. All criteria are based on clinical experience to be practical, and further studies are necessary before the widespread use of these criteria can occur. Symptoms must meet all major criteria and at least one of the minor criteria to obtain a definite diagnosis of RAS. 


\section{Statistical analysis}

The original data from the paper questionnaire were processed and transcribed to Excel and the Statistical Package for the Social Science 22.0 to set up a database of the results. All categorical variables are described by frequencies and percentages. The validity and reliability of the questionnaire were performed, and univariable analysis was performed to obtain a preliminary result and screen out variables with little evidence of association. Variables with a $p$ value $<.05$ in the univariable analysis were included in multivariable regression analysis to evaluate the connection between the dietary factors and RAS. The multivariable logistic regression was adjusted for age and gender, and statistical significance was defined as $p<.05$.

\section{Results}

\section{Reliability and validity of the questionnaire}

Cronbach's a for the questionnaire was 0.797 , indicating that it demonstrated good reliability; in addition, the KMO value was 0.883 , and the X2 value in Bartlett's test of sphericity was $70.598(p<.05)$, suggesting good validity.

\section{Participant characteristics}

A total of 754 participants consisting of 336 males and 418 females were enrolled in this study, with a RAS prevalence of $21.4 \%$. The demographics of the participants are summarized in Table 3 . There was no significant difference in gender $(p>.05)$ or age $(p>.05)$ among RAS or non-RAS participants according to univariable analysis.

The self-reported trigger factors and therapeutic methods of the RAS group $(161,21.4 \%)$ are summarized in Table 4. A total of $53.4 \%, 56.5 \%, 69.6 \%, 69.6 \%$, and $78.9 \%$ of the RAS group self-reported stress, reduced immune function, irregular life schedule, and unhealthy diet as a trigger factor, respectively, and the distribution of trigger factors in the various age groups is shown in Fig 1. Nearly half $(89,55.3 \%)$ of the participants were not undergoing treatment for RAS, while $29.2 \%$ and $15.5 \%$ of the RAS group chose conventional medicine or alternative treatments (ATs), respectively.

\section{Associations of dietary factors with RAS}

The distribution of the prevalence of RAS in groups with different dietary habits is shown in Fig 2, and Table 5 presents the preliminary results of the relationship between RAS and putative dietary factors from the univariable analysis, showing RAS negatively associated with fruit, dairy, drinking water, and vegetable $(p<.05)$. Other variables, including fried foods, fermented foods, spicy foods, and eggs, showed no significant correlations $(p \geq .05)$. The significant variables were all included in the multivariable logistic regression, which was adjusted for age and gender, as shown in Table 6 and Fig 3 . After adjustment for the confounders, the multivariable logistic regression revealed that RAS negatively 
associated with fruit (adjusted odds ratio [aOR] $=.430,95 \%$ confidence interval $[\mathrm{Cl}]=[.218-.847], p=.015)$ and drinking water $(\mathrm{aOR}=.294,95 \% \mathrm{Cl}=[.119-.726], p=.008)$.

\section{Discussion}

In this cross-sectional study, we explored the distribution of RAS, dietary factors, self-reported trigger factors, and therapeutic methods among a study population from Nanjing and reported a prevalence of $21.4 \%$ in accordance with the literature $[14,24,25]$. Moreover, less than half $(72,44.7 \%)$ of them had ever received treatment for RAS, which was lower than the percentage reported in another study [21,26], and nearly one-third participants who have ever treated RAS mainly use ATs instead of conventional medicine, despite a lack of randomized controlled trials to prove the effectiveness and safety of these ATs. These results indicated that patient education on the importance of RAS treatment is needed.

The univariable analysis revealed that RAS is negatively associated with fruit (OR $=.402)$, dairy (OR $=.470)$, drinking water $(\mathrm{OR}=.224)$, and vegetable $(\mathrm{OR}=0.619)(p<.05)$, while RAS is not significant associated with other factors, including vegetable, fried foods, fermented foods, spicy foods, eggs, gender, and age $(p \geq 05)$. Zinc and probiotics in dairies may explain the preventive mechanisms of dairies in RAS [27-35]. Several studies have suggested lower levels of serumal zinc of RAS patients compared with health control, and a role of zinc in ulcer healing and free-radical scavenging to treat RAS [31-33]. Other studies have reported a change of microbiomes in RAS, and a treatment effect of

Lactobacillus and Bifidobacterium composition on RAS. Zinc and selenium in vegetables may explain the preventive mechanisms of vegetable in RAS $[34,35]$. Zinc has been suggested to involve in the synthesis of protein and collagen, which contribute to wound healing, while selenium supplementation has been suggested to associate with a decrement of peroxidation lipids and incidence of infectious complications, as well as better wound healing [10, 36-39].

Another finding of our study was that multivariable logistic regression suggests that RAS positively associated with fruit $(\mathrm{aOR}=.430)$ and drinking water $(\mathrm{aOR}=.294)(p<.05)$. It is noteworthy that RAS was first found to be associated with the total consumption of fruit and drinking water in this study. Considering the significant decrease of folate in RAS patients compared with health controls found in several studies and the capacity of vitamin $C$ to reduce outbreaks and pain level of minor recurrent aphthous stomatitis (MRAS) [1, 5, 40,41], fruits may prevent RAS by supplementing folate and vitamin C. Considering the capacity of calcium to protect oral mucous and regulates the immune capacity by maintaining the polarity of tissue $[42,43]$ and the capacity of magnesium to reduce both serum nitric oxide and lipid peroxidation to treat ulcers in mouse model [44], drinking water may prevent RAS by supplementing calcium and magnesium.

We acknowledge a bias towards a younger population which might result from a high percentage of students in the chosen neighbourhood communities. However, considering that no significant association was found between age and RAS in this study, this bias should not affect the generalizability of our results. Nevertheless, despite our attempts to choose districts representative of different demographic 
statuses, including participants solely from Nanjing poses some inevitable limitations on the generalizability and extrapolation of the results to other urban and rural areas.

\section{Conclusion}

The present study indicated that the consumptions of fruits and drinking water might be potential protective factors of RAS and consumption of fruits and drinking water might be valuable as daily preventive measures for RAS. These results could provide new insights into the prevention and treatment of RAS.

\section{Abbreviations}

RAS: recurrent aphthous stomatitis; CMP:cow's milk protein; ATs:alternative treatments; aOR:adjusted odds ratio; Cl:confidence interval; MRAS:minor recurrent aphthous stomatitis

\section{Declarations}

\section{Acknowledgements}

Not applicable.

\section{Authors' contributions}

WM Wang conceived and supervised this study. X Wang co-supervised, co-designed, and co-conducted this study. KY Xu and CC Zhou designed the study, conducted the survey, conducted the statistical analysis, designed the framework of the manuscript, and drafted the manuscript. YY Wang and N Duan co-designed the study and conducted the survey. LC Zhen participated in data processing and analysis. All the authors have read and approved the final manuscript.

\section{Funding}

This work is supported by the Natural Scientific Foundation of China ( 81870767 \& 81570978), the Key Project of Science and Technology Department of Jiangsu Province (BL2014018), the Project of Jiangsu Provincial Medical Youth Talent (QNRC2016118), the Preventive Medicine Project of Jiangsu Province (Y2015004), and the Nanjing Medical Science and Technique Development Foundation (ZKX17033 \& YKK16162).

\section{Availability of data and materials}

The data supporting this study are available from the corresponding author on reasonable request.

\section{Ethics approval and consent to participate}


Informed consent was obtained from each participant, and the Ethics Committee of Nanjing

Stomatological Hospital confirmed this form of consent and approved this survey (2014NL-002 (KS)). All participants joined voluntarily and were informed of their rights to withdraw from the survey at any time. The participants answered the questionnaires anonymously.

Consent for publication

Not applicable.

Declaration of conflicting interest

The authors declare no potential conflicts of interest with respect to the research, authorship, or publication of this article.

\section{References}

1. Yasui K, Kurata T, Yashiro M, Tsuge M, Ohtsuki S, Morishima $T$ : The effect of ascorbate on minor recurrent aphthous stomatitis. Acta Paediatr 2010, 99(3):442-445.

2. Giannetti L, Murri Dello Diago A, Lo Muzio L: Recurrent aphtous stomatitis. Minerva Stomato/ 2018, 67(3):125-128.

3. Bilodeau EA, Lalla RV: Recurrent oral ulceration: Etiology, classification, management, and diagnostic algorithm. Periodontol 2000 2019, 80(1):49-60.

4. Queiroz S, Silva M, Medeiros AMC, Oliveira PT, Gurgel BCV, Silveira É JDD: Recurrent aphthous ulceration: an epidemiological study of etiological factors, treatment and differential diagnosis. $A n$ Bras Dermatol 2018, 93(3):341-346.

5. Chiang CP, Yu-Fong Chang J, Wang YP, Wu YH, Wu YC, Sun A: Recurrent aphthous stomatitis Etiology, serum autoantibodies, anemia, hematinic deficiencies, and management. $J$ Formos Med Assoc 2019, 118(9):1279-1289.

6. Saikaly SK, Saikaly TS, Saikaly LE: Recurrent aphthous ulceration: a review of potential causes and novel treatments. J Dermatolog Treat 2018, 29(6):542-552.

7. Chainani-Wu N, Nayudu A: Resolution of recurrent aphthous ulcers after discontinuation of cow's milk protein intake. J Am Dent Assoc 2017, 148(8):614-617.

8. Besu I, Jankovic L, Konic-Ristic A, Damjanovic A, Besu V, Juranic Z: Good tolerance to goat's milk in patients with recurrent aphthous ulcers with increased immunoreactivity to cow's milk proteins. Journal of oral pathology \& medicine : official publication of the International Association of Oral Pathologists and the American Academy of Oral Pathology 2013, 42(7):523-527.

9. Shi L, Wan K, Tan M, Yin G, Ge M, Rao X, He L, Jin Y, Yao Y: Risk factors of recurrent aphthous ulceration among university students. Int J Clin Exp Med 2015, 8(4):6218-6223.

10. Lin K-C, Tsai LL, Ko EC, Sheng-Po Yuan K, Wu S-Y: Comorbidity profiles among patients with recurrent aphthous stomatitis: A case-control study. J Formos Med Assoc 2019, 118(3):664-670. 
11. Shakeri R, Zamani F, Sotoudehmanesh R, Amiri A, Mohamadnejad M, Davatchi F, Karakani AM, Malekzadeh R, Shahram F: Gluten sensitivity enteropathy in patients with recurrent aphthous stomatitis. BMC Gastroentero/ 2009, 9:44.

12. Slebioda Z, Szponar E, Kowalska A: Etiopathogenesis of recurrent aphthous stomatitis and the role of immunologic aspects: literature review. Arch Immunol Ther Exp (Warsz) 2014, 62(3):205-215.

13. Tarakji B, Baroudi $K$, Kharma Y: The effect of dietary habits on the development of the recurrent aphthous stomatitis. Niger Med J 2012, 53(1):9-11.

14. Du Q, Ni S, Fu Y, Liu S: Analysis of Dietary Related Factors of Recurrent Aphthous Stomatitis among College Students. Evid Based Complement Alternat Med 2018, 2018:2907812.

15. Nanri H, Yamada Y, Itoi A, Yamagata E, Watanabe Y, Yoshida T, Miyake M, Date H, Ishikawa-Takata K, Yoshida $\mathrm{M}$ et al: Frequency of Fruit and Vegetable Consumption and the Oral Health-Related Quality of Life among Japanese Elderly: A Cross-Sectional Study from the Kyoto-Kameoka Study. Nutrients 2017, 9(12).

16. Bradshaw PT, Siega-Riz AM, Campbell M, Weissler MC, Funkhouser WK, Olshan AF: Associations between dietary patterns and head and neck cancer: the Carolina head and neck cancer epidemiology study. Am J Epidemio/2012, 175(12):1225-1233.

17. Ma R, Chen H, Zhou T, Chen X, Wang C, Chen Y, Rao S, Ge L, Lin M: Effect of bedtime on recurrent aphthous stomatitis in college students. Oral Surg Oral Med Oral Pathol Oral Radiol 2015, 119(2):196-201.

18. Gallus S, Bosetti C, Franceschi S, Levi F, Negri E, La Vecchia C: Laryngeal cancer in women: tobacco, alcohol, nutritional, and hormonal factors. Cancer Epidemiol Biomarkers Prev 2003, 12(6):514-517.

19. Global, regional, and national incidence, prevalence, and years lived with disability for 328 diseases and injuries for 195 countries, 1990-2016: a systematic analysis for the Global Burden of Disease Study 2016. Lancet 2017, 390(10100):1211-1259.

20. Wang H, Dwyer-Lindgren L, Lofgren KT, Rajaratnam JK, Marcus JR, Levin-Rector A, Levitz CE, Lopez AD, Murray CJ: Age-specific and sex-specific mortality in 187 countries, 1970-2010: a systematic analysis for the Global Burden of Disease Study 2010. Lancet 2012, 380(9859):2071-2094.

21. Sawair FA: Recurrent aphthous stomatitis: do we know what patients are using to treat the ulcers? $J$ Altern Complement Med 2010, 16(6):651-655.

22. Wang SS, Lay S, Yu HN, Shen SR: Dietary Guidelines for Chinese Residents (2016): comments and comparisons. J Zhejiang Univ Sci B 2016, 17(9):649-656.

23. Natah SS, Konttinen YT, Enattah NS, Ashammakhi N, Sharkey KA, Häyrinen-Immonen R: Recurrent aphthous ulcers today: a review of the growing knowledge. Int J Oral Maxillofac Surg 2004, 33(3):221-234.

24. Souza PRM, Duquia RP, Breunig JA, Almeida HL, Jr.: Recurrent aphthous stomatitis in 18-year-old adolescents - Prevalence and associated factors: a population-based study. An Bras Dermato/ 2017, 92(5):626-629. 
25. Ajmal M, Ibrahim L, Mohammed N, Al-Qarni H: Prevalence and psychological stress in recurrent aphthous stomatitis among female dental students in Saudi Arabia. Clujul Med 2018, 91(2):216-221.

26. Vucicevic Boras V, Savage NW: Recurrent aphthous ulcerative disease: presentation and management. Aust Dent J 2007, 52(1):10-73.

27. Al-Amad SH, Hasan $\mathrm{H}$ : Vitamin $\mathrm{D}$ and hematinic deficiencies in patients with recurrent aphthous stomatitis. Clin Oral Investig 2020, 24(7):2427-2432.

28. Bahramian A, Falsafi P, Abbasi T, Ghanizadeh M, Abedini M, Kavoosi F, Kouhsoltani M, Noorbakhsh F, Dabbaghi Tabriz F, Rajaeih S et al: Comparing Serum and Salivary Levels of Vitamin D in Patients with Recurrent Aphthous Stomatitis and Healthy Individuals. J Dent (Shiraz) 2018, 19(4):295-300.

29. Pontes HA, Neto NC, Ferreira KB, Fonseca FP, Vallinoto GM, Pontes FS, Pinto Ddos S, Jr.: Oral manifestations of vitamin B12 deficiency: a case report. J Can Dent Assoc 2009, 75(7):533-537.

30. Yıldırımyan N, Özalp Ö, Şatır S, Altay MA, Sindel A: Recurrent Aphthous Stomatitis as a Result of Zinc Deficiency. 2019.

31. Ozturk P, Belge Kurutas E, Ataseven A: Copper/zinc and copper/selenium ratios, and oxidative stress as biochemical markers in recurrent aphthous stomatitis. J Trace Elem Med Bio/2013, 27(4):312316.

32. Ozler GS: Zinc deficiency in patients with recurrent aphthous stomatitis: a pilot study. J Laryngol Otol 2014, 128(6):531-533.

33. Bao ZX, Yang XW, Shi J, Liu LX: Serum zinc levels in $\mathbf{3 6 8}$ patients with oral mucosal diseases: A preliminary study. Med Oral Patol Oral Cir Bucal 2016, 21(3):e335-340.

34. Mimura MAM, Borra RC, Hirata CHW, de Oliveira Penido N: Immune response of patients with recurrent aphthous stomatitis challenged with a symbiotic. J Oral Pathol Med 2017, 46(9):821-828.

35. Yang Z, Cui Q, An R, Wang J, Song X, Shen Y, Wang M, Xu H: Comparison of microbiomes in ulcerative and normal mucosa of recurrent aphthous stomatitis (RAS)-affected patients. BMC Oral Health 2020, 20(1):128.

36. Lin Q, Xie YD, Xie QQ, Zheng X: [Case-control study on risk factors of recurrent aphthous ulcer]. Shanghai Kou Qiang Yi Xue 2019, 28(1):53-56.

37. Żwierełło W, Styburski D, Maruszewska A, Piorun K, Skórka-Majewicz M, Czerwińska M, Maciejewska D, Baranowska-Bosiacka I, Krajewski A, Gutowska I: Bioelements in the treatment of burn injuries The complex review of metabolism and supplementation (copper, selenium, zinc, iron, manganese, chromium and magnesium). J Trace Elem Med Biol 2020, 62:126616.

38. Prasad AS: Zinc: role in immunity, oxidative stress and chronic inflammation. Curr Opin Clin Nutr Metab Care 2009, 12(6):646-652.

39. Chasapis CT, Ntoupa PA, Spiliopoulou CA, Stefanidou ME: Recent aspects of the effects of zinc on human health. Arch Toxicol 2020, 94(5):1443-1460.

40. Bao ZX, Shi J, Yang XW, Liu LX: Hematinic deficiencies in patients with recurrent aphthous stomatitis: variations by gender and age. Med Oral Patol Oral Cir Bucal 2018, 23(2):e161-e167. 
41. Wu YC, Wu YH, Wang YP, Chang JY, Chen HM, Sun A: Hematinic deficiencies and anemia statuses in recurrent aphthous stomatitis patients with or without atrophic glossitis. J Formos Med Assoc 2016, 115(12):1061-1068.

42. Lingyong J, Bing $\mathrm{F}$, Lina $\mathrm{H}$, Chao W: Calcium regulating the polarity: a new pathogenesis of aphthous ulcer. Med Hypotheses 2009, 73(6):933-934.

43. Nagai $\mathrm{N}$, Takeda $\mathrm{A}$, Itanami $\mathrm{Y}$, Ito $\mathrm{Y}$ : Co-administration of water containing magnesium ion prevents loxoprofen-induced lesions in gastric mucosa of adjuvant-induced arthritis rat. Biol Pharm Bull 2012, 35(12):2230-2237.

44. Ige AO, Adewoye EO, Okwundu NC, Alade OE, Onuobia PC: Oral magnesium reduces gastric mucosa susceptibility to injury in experimental diabetes mellitus. Pathophysiology 2016, 23(2):87-93.

\section{Appendix}

\section{SPECIFIC FOODS}

Dear participants:

Thank you for participating in this survey! The questionnaire was designed to explore potential, simple, and feasible preventive methods for RAS through analyzing the potential relationship between specific dietary factors and recurrent aphthous stomatitis (RAS). We would never disclose any of your personal information and the information that you fill in will only be used in our research. Please select an option and mark it with "O".

P.S.: Ethics Committee of Nanjing Stomatological Hospital confirmed this form of consent and approved this survey (2014NL-002 (KS)). According to the description of Dietary Guidelines for Chinese Residents (2016), daily consumptions of fruit, dairy, drinking water, and vegetable were estimated and classified into different levels; Consumption frequencies of other dietary factors were classified into three categories: never or seldom, sometimes (1-3 times per week), often (at least 4 times per week).

1. Gender:
A. Male
B. Female

2. Age:

A.18-29

B. $30-44$

C. $45-59$ 
3. History of RAS ${ }^{1}$ :
A. Yes
B. No

History of RAS ${ }^{1}$ : To definite a RAS history, symptoms must meet all major criteria and at least one of the minor criteria in table 1 and table 2.

Table 1. Major criteria for RAS

\begin{tabular}{|ll|}
\hline Major criteria & Description \\
\hline $\begin{array}{l}\text { 1. Appearance } \\
\text { 2. Recurrence }\end{array}$ & $\begin{array}{l}\text { Multiple, small, ovoid, recurrent ulcers with erythematous haloes, circumscribed } \\
\text { margins, and yellow or grey floors. }\end{array}$ \\
\hline $\begin{array}{l}\text { Averagely one occurrence of RAS yearly at least and the recurrence does not } \\
\text { affect the same site. }\end{array}$ \\
\hline $\begin{array}{l}\text { 4. Self-limitation } \\
\text { Ayperalgesia }\end{array}$ & A symptom of painful lesions and movement of lesion can exacerbate pain. \\
\hline
\end{tabular}

\begin{tabular}{|ll|}
\hline \multicolumn{2}{|l|}{ Table 2. Minor criteria for RAS } \\
\hline Minor criteria & Description \\
\hline 1. Family history of RAS & Presence of the RAS in at least one first-degree relative. \\
\hline 2. Location of ulcers & Non-keratinized oral mucosa. \\
\hline 3. Duration & Several days to two weeks. \\
\hline 4. Precipitating factors & Stress, local trauma and infections. \\
\hline 5. Smoking & Non-smoker. \\
\hline
\end{tabular}

4. Over the past 12 months, how many fruits ${ }^{2}$ do you consume per day on average?
A. $\leq 100 \mathrm{~g}$
B. $>100 \mathrm{~g}$ and $\leq 200 \mathrm{~g}$
C. $>100 \mathrm{~g}$ and $\leq 200 \mathrm{~g}$
D. $>300 \mathrm{~g}$ 
Fruits ${ }^{2}$ : Fruits include drupe, berry, melon, pome, citrus fruits.

5. Over the past 12 months, how many dairies ${ }^{3}$ do you consume per day on average?

A.Hardly or never ${ }^{4}$

B. $\leq 100 \mathrm{~g}$

C. $>100 \mathrm{~g}$ and $\leq 200 \mathrm{~g}$

D. $>200 \mathrm{~g}$

Dairies $^{3}$ : Dairies include skim/low-fat and whole milk, condensed milk, milk powder, milk tablets, liquid yogurt, curd yogurt, ice-cream, cheese, and butter;

Hardly or never ${ }^{4}$ : Specific food is consumed less than once week and the consumption is hard to quantify.

6. Over the past 12 months, how much drinking water ${ }^{5}$ do you consume per day on average?
A.Hardly or never
B. $>1000 \mathrm{ml}$
C. $>1000 \mathrm{ml}$ and $\leq 2000 \mathrm{~mL}$
D. $>2000 \mathrm{~mL}$

Drinking water ${ }^{5}$ : Drinking water includes plain drinking water (bottled water and tap water) and beverages (soft drinks, energy drinks, alcoholic drinks, milk, coffee, juice, tea, and other beverage drinks), but not moisture of food.

7. Over the past 12 months, how many vegetables ${ }^{6}$ do you consume per day on average?
A. $\leq 100 \mathrm{~g}$
B. $>100 \mathrm{~g}$

$V_{\text {Vegetables }}^{6}$ : Vegetables include Cruciferae, Umbelliferae, Leguminosae, Solanum, Chenopodiaceae, and Cucurbitaceae.

8. Over the past 12 months, how often do you eat high-temp foods ${ }^{7}$ ?

A.Never or seldom ${ }^{8}$

B.Sometimes ${ }^{9}$ 
C.Often ${ }^{10}$

High-temp foods ${ }^{7}$ : High-temp foods include hot soup, hot tea, hot pot and other foods with high temperature.

Never or seldom ${ }^{8}$ : Specific food is consumed less than once a week.

Sometimes ${ }^{9}$ : Specific food is consumed 1-3 times per week.

Often ${ }^{10}$ : Specific food is consumed at least 4 times per week.

9. Over the past 12 months, how often do you consume spicy foods?
A. Never or seldom
B. Sometimes
C. Often

10. Over the past 12 months, how often do you consume fried foods?
A. Never or seldom
B. Sometimes
C. Often

11. Over the past 12 months, how often do you consume fermented ${ }^{11}$ foods?
A. Never or seldom
B. Sometimes
C. Often

Fermented foods ${ }^{11}$ : Fermented foods include pickles, kimchi, and sauerkraut, but not yoghourt.

Several dietary factors, including high-temp food, spicy food, fried food, and fermented food, have been suggested as topical irritate positively associated with RAS. Their physico-chemical properties can topically irritate the oral mucosa and lead to RAS.

12. Do you consume eggs?
A. Never or seldom
B. Sometimes or often 
If you never experienced RAS, you could stop here. Thank you very much for your cooperation! Do you have any comments or suggestions for this survey?

13. Which factors might associate with your RAS? (multiple choice)
A. Stress
B. Immune function reduction
C. Irregular life schedule
D. Unhealthy diet ${ }^{12}$
E. Others or no

Unhealthy diet ${ }^{12}$ : Experiences of RAS in several hours after consuming high-temp food, spicy food, fried food, or fermented food.

14. Which foods might be unhealthy diets and risk factors of RAS?
A. high-temp food
B. spicy food
C. fried food
D. fermented food
E. Others or no

15. What is the main method that you choose to deal with RAS?
A. Conventional medicines ${ }^{13}$
B. Alternative treatments ${ }^{14}$
C. No treatment

Conventional medicines ${ }^{13}$ : Conventional medicines includes topical anesthetic/analgesic, topical steroid, covering agent, antibiotics, antifungals, antiseptic mouthwash, vitamins.

Alternative treatments ${ }^{14}$ : Alternative medicines includes sodium bicarbonate solution, sodium bicarbonate powder, salt water, warm water, lemon, lemon salt, chamomile, others (coffee, ice, strawberry, berry, olive oil, yeast, tomato paste, castor oil, squeezing ulcers, smoking).

Thank you very much for your cooperation! Do you have any comments or suggestions for this survey? 


\section{Tables}

\begin{tabular}{|c|c|c|c|c|c|c|c|}
\hline \multicolumn{8}{|c|}{ Table 3. Demographics of the subjects } \\
\hline & & \multirow[t]{2}{*}{$N$} & \multicolumn{2}{|l|}{ RAS } & \multirow[t]{2}{*}{ OR } & \multirow[t]{2}{*}{$95 \% \mathrm{Cl}$} & \multirow[t]{2}{*}{$P$} \\
\hline & & & Yes (\%) & No (\%) & & & \\
\hline \multirow[t]{2}{*}{ Gender } & Male & 336 & $72(45)$ & $264(45)$ & 1.000 & & \\
\hline & Female & 418 & $89(55)$ & 329 (55) & 0.992 & $0.699-1.408$ & 0.964 \\
\hline \multirow[t]{3}{*}{ Age } & $18-29$ & 576 & $117(73)$ & 459 (77) & 1.000 & & \\
\hline & $30-44$ & 114 & $29(18)$ & $85(14)$ & 1.338 & $0.838-2.137$ & 0.222 \\
\hline & $45-59$ & 64 & $15(9)$ & 49 (8) & 1.201 & $0.651-2.217$ & 0.558 \\
\hline
\end{tabular}

Table 4. Self-reported trigger factors and the main therapeutic methods in different age groups

$\begin{array}{lll}n(\%) & & \\ 18-29 & 30-45 & 46-59 \\ (\mathrm{~N}=117) & (\mathrm{N}=29) & (\mathrm{N}=15)\end{array}$

Self-reported trigger factors (multiple choice)

\begin{tabular}{lllll} 
Stress & $64(55)$ & $14(48)$ & $8(53)$ & 53.4 \\
\hline Reduced immune function & $61(52)$ & $19(66)$ & $11(73)$ & 56.5 \\
\hline Irregular life schedule & $84(72)$ & $19(66)$ & $9(60)$ & 69.6 \\
\hline Unhealthy diet & $99(85)$ & $17(59)$ & $11(73)$ & 78.9 \\
\hline Others or no & $22(19)$ & $6(21)$ & $3(20)$ & 19.3 \\
\hline Therapeutic methods & & & & \\
Conventional medicines & $30(26)$ & $10(35)$ & $7(47)$ & 29.2 \\
\hline Alternative treatments & $14(12)$ & $7(24)$ & $4(27)$ & 15.5 \\
\hline No treatment & $73(62)$ & $12(41)$ & $4(27)$ & 55.3
\end{tabular}

Unhealthy diet: Experiences of RAS in several hours after consuming high-temp food, spicy food, fried food, or fermented food. 
Table 5. univariate analysis of the relationship between dietary factors and RAS

\begin{tabular}{|llllll} 
Variables & RAS (\%) & Control (\%) & OR & $95 \% \mathrm{Cl}$ & $P$ \\
\hline Fruit & & & & & \\
\hline$\leq 100 \mathrm{~g}$ & $64(40)$ & $178(30)$ & 1.000 & & \\
\hline$\geq 100 \mathrm{~g}$ and $\leq 200 \mathrm{~g}$ & $78(48)$ & $299(50)$ & 0.726 & $0.497-1.060$ & 0.097 \\
\hline$\geq 200 \mathrm{~g}$ and $\leq 300 \mathrm{~g}$ & $13(8)$ & $90(15)$ & 0.402 & $0.210-0.768$ & 0.006 \\
\hline$\geq 300 \mathrm{~g}$ & $6(4)$ & $26(4)$ & 0.642 & $0.253-1.631$ & 0.351 \\
\hline Dairy & & & & &
\end{tabular}

Hardly or never

$28(17)$

71 (12)

1.000

$\leq 100 \mathrm{~g}$

$44(27)$

$185(31)$

0.603

$0.349-1.042$

0.070

$>100 \mathrm{~g}$ and $\leq 200 \mathrm{~g}$

$74(46)$

$256(43)$

0.733

$0.441-1.218$

0.231

$>200 \mathrm{~g}$

15 (9)

81 (14)

0.470

0.232-0.949

0.035

Drinking water

Hardly or never

$\leq 1000 \mathrm{ml}$

$11(7)$

11 (2)

$>1000 \mathrm{ml}$ and $\leq 2000 \mathrm{ml}$

50 (31)

198 (33)

0.253

0.104-0.616

0.002

$>2 \mathrm{~L}$

85 (53)

317 (53)

0.268

0.122-0.640

0.003

$>2 \mathrm{~L}$

15 (9)

67 (11)

0.224

0.082-0.612

0.004

Vegetable

$\leq 100 \mathrm{~g}$

29 (18)

132 (12)

1.000

$>100 \mathrm{~g}$

132 (82)

522 (88)

0.619

$0.386-0.993$

0.047

High-temp foods

Never or seldom

Sometimes

Often

70 (43)

273 (46)

1.000

69 (43)

257 (43)

1.047

0.721-1.521

0.809

22 (14)

63 (11)

1.362

0.784-2.365

0.273

Spicy foods

Never or seldom

Sometimes

22 (14)

94 (16)

1.000

Often

$87(54)$

$354(60)$

1.050

0.624-1.766

0.854

52 (32)

145 (24)

1.532

$0.874-2.688$

0.137

Fried foods 


\begin{tabular}{|c|c|c|c|c|c|}
\hline Never or seldom & $33(20)$ & $114(19)$ & 1.000 & & \\
\hline Sometimes & $102(63)$ & 397 (67) & 0.888 & $0.569-1.384$ & 0.599 \\
\hline Often & $26(16)$ & $82(14)$ & 1.095 & $0.609-1.970$ & 0.761 \\
\hline \multicolumn{6}{|l|}{ Fermented foods } \\
\hline Never or seldom & $61(38)$ & $214(36)$ & 1.000 & & \\
\hline Sometimes & $94(58)$ & $363(61)$ & 0.908 & $0.631-1.307$ & 0.605 \\
\hline Often & $6(4)$ & $16(3)$ & 1.316 & $0.494-3.507$ & 0.583 \\
\hline \multicolumn{6}{|l|}{ Eggs } \\
\hline Sometimes or often & $158(98)$ & $568(96)$ & 1.000 & & \\
\hline Never or seldom & $3(2)$ & $25(4)$ & 2.318 & $0.691-7.777$ & 0.173 \\
\hline \multicolumn{6}{|c|}{$\begin{array}{l}\text { Hardly or never: Specific food is consumed less than once week and the consumption is hard to } \\
\text { quantify. }\end{array}$} \\
\hline \multicolumn{6}{|c|}{ Never or seldom: Special food is consumed less than once a week. } \\
\hline \multicolumn{6}{|c|}{ Sometimes: Special food is consumed 1-3 times per week. } \\
\hline \multicolumn{6}{|c|}{ Often: Special food is consumed at least 4 times per week. } \\
\hline \multicolumn{6}{|c|}{ Boldface values are statistically significant to $P<0.05$. } \\
\hline \multicolumn{6}{|c|}{ Abbreviations: RAS, recurrent aphthous stomatitis; $\mathrm{Cl}$, confidence interval; OR, odds ratio. } \\
\hline
\end{tabular}


Table 6. Multivariate logistic regression of the relationship between dietary factors and RAS

$\begin{array}{lllll}\text { Variable } & \begin{array}{l}\text { RAS } \\ (\%)\end{array} & \begin{array}{l}\text { Control } \\ (\%)\end{array} & \begin{array}{l}\text { Unadjusted OR } \\ (95 \% \mathrm{Cl}, P \text { Value })\end{array} & \begin{array}{l}\text { Adjusted OR } \\ (95 \% \mathrm{Cl}, P \text { Value })^{a}\end{array} \\ & & & & \end{array}$

Fruit

$\leq 100 \mathrm{~g} \quad 64(40) \quad 178(30) \quad 1 \quad 1$

$\begin{array}{llll}>100 \mathrm{~g} \text { and } \leq 200 \mathrm{~g} \quad 78(48) & 299(50) & \begin{array}{l}0.756(0.505-1.132, \\ 0.175)\end{array} & \begin{array}{l}0.740 \\ 0.149)\end{array}\end{array}$

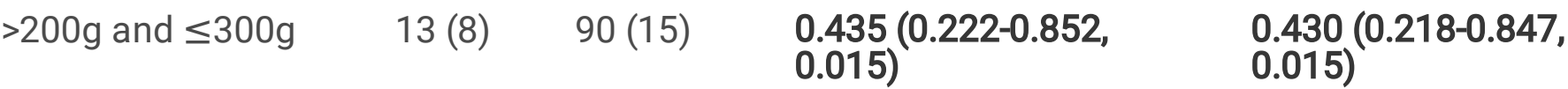

\begin{tabular}{|c|c|c|c|}
\hline$>300 \mathrm{~g}$ & $6(4)$ & $26(4)$ & $\begin{array}{l}0.755(0.289-1.970, \\
0.566)\end{array}$ \\
\hline
\end{tabular}

Dairy

Hardly or never

$28(17) \quad 71(12)$

1

1

$\leq 100 \mathrm{~g}$

$44(27) \quad 185(31)$

$0.682(0.389-1.197$,

$0.183)$

$0.716(0.403-1.269$,

$0.252)$

$>100 \mathrm{~g}$ and $\leq 200 \mathrm{~g}$

$74(46) \quad 256(43)$

0.922 (0.539-1.577,

0.996 (0.565-1.756,

$0.765)$

0.990)

$>200 \mathrm{~g}$

$15(9)$

$81(14)$

0.573 (0.276-1.187,

0.134 )

0.632 (0.294-1.358,

0.240 )

Drinking water

\begin{tabular}{|c|c|c|c|c|}
\hline Hardly or never & $11(7)$ & $11(2)$ & 1 & 1 \\
\hline$\leq 1000 \mathrm{ml}$ & $50(31)$ & 198 (33) & $\begin{array}{l}0.290(0.117-0.717 \\
0.007)\end{array}$ & $\begin{array}{l}0.294(0.119-0.726, \\
0.008)\end{array}$ \\
\hline $\begin{array}{l}>1000 \mathrm{ml} \text { and } \\
<2000 \mathrm{ml}\end{array}$ & $85(53)$ & 317 (53) & $\begin{array}{l}0.338(0.138-0.826, \\
0.017)\end{array}$ & $\begin{array}{l}0.343(0.140-0.843, \\
0.020)\end{array}$ \\
\hline$>2 \mathrm{~L}$ & $15(9)$ & $67(11)$ & $\begin{array}{l}0.277(0.099-0.773, \\
0.014)\end{array}$ & $\begin{array}{l}0.276(0.098-0.777 \\
0.015)\end{array}$ \\
\hline
\end{tabular}

Vegetable

$\begin{array}{lllll}\leq 100 \mathrm{~g} & 29(18) & 132(12) & 1 & 1 \\ >100 \mathrm{~g} & 132 & 522(88) & 0.697(0.421-1.152, & 0.683(0.412-1.131, \\ & (82) & & 0.159) & 0.138)\end{array}$

Hardly or never: Specific food is consumed less than once week and the consumption is hard to quantify.

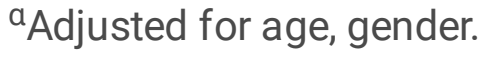

Boldface values are statistically significant to $P<0.05$. 
Figures

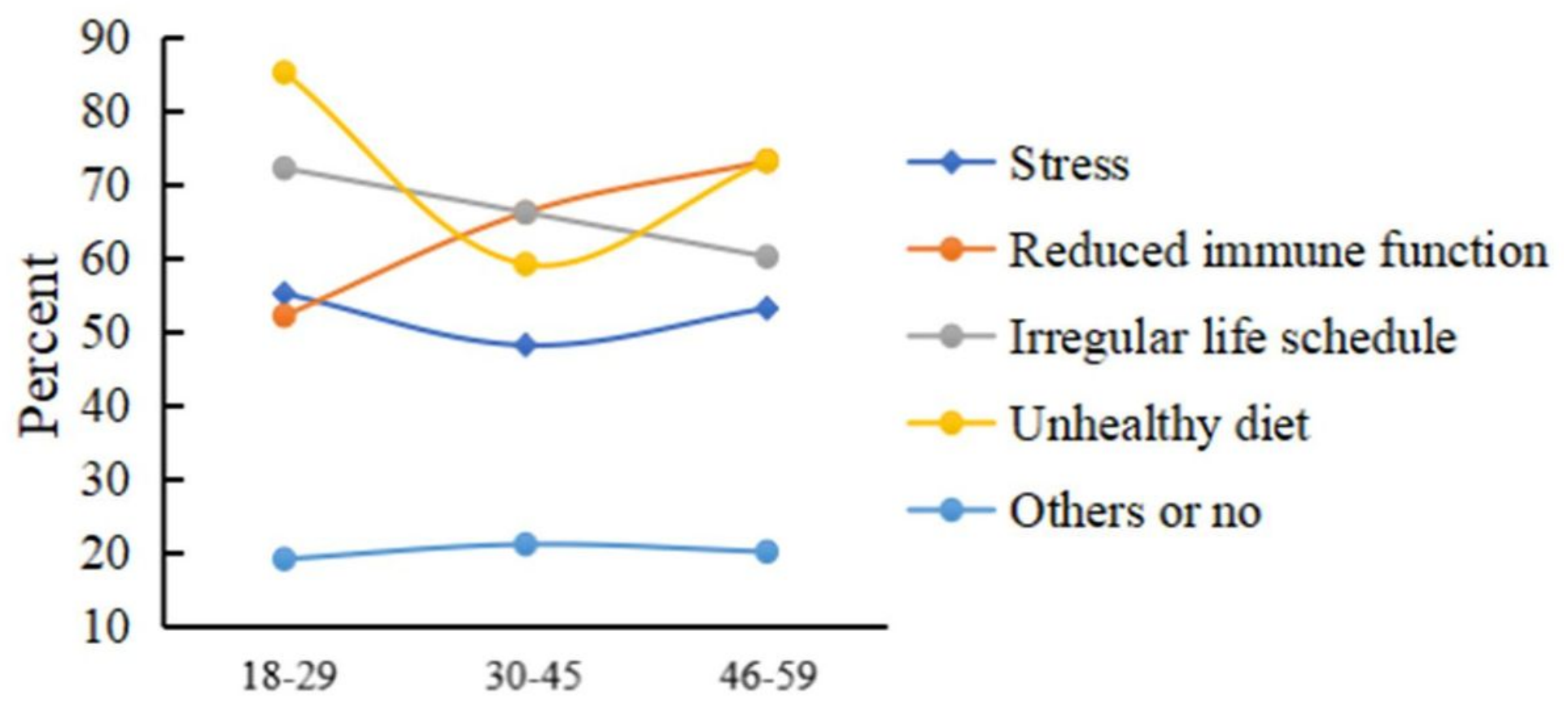

Figure 1

Distribution of trigger factors in the different age groups. 

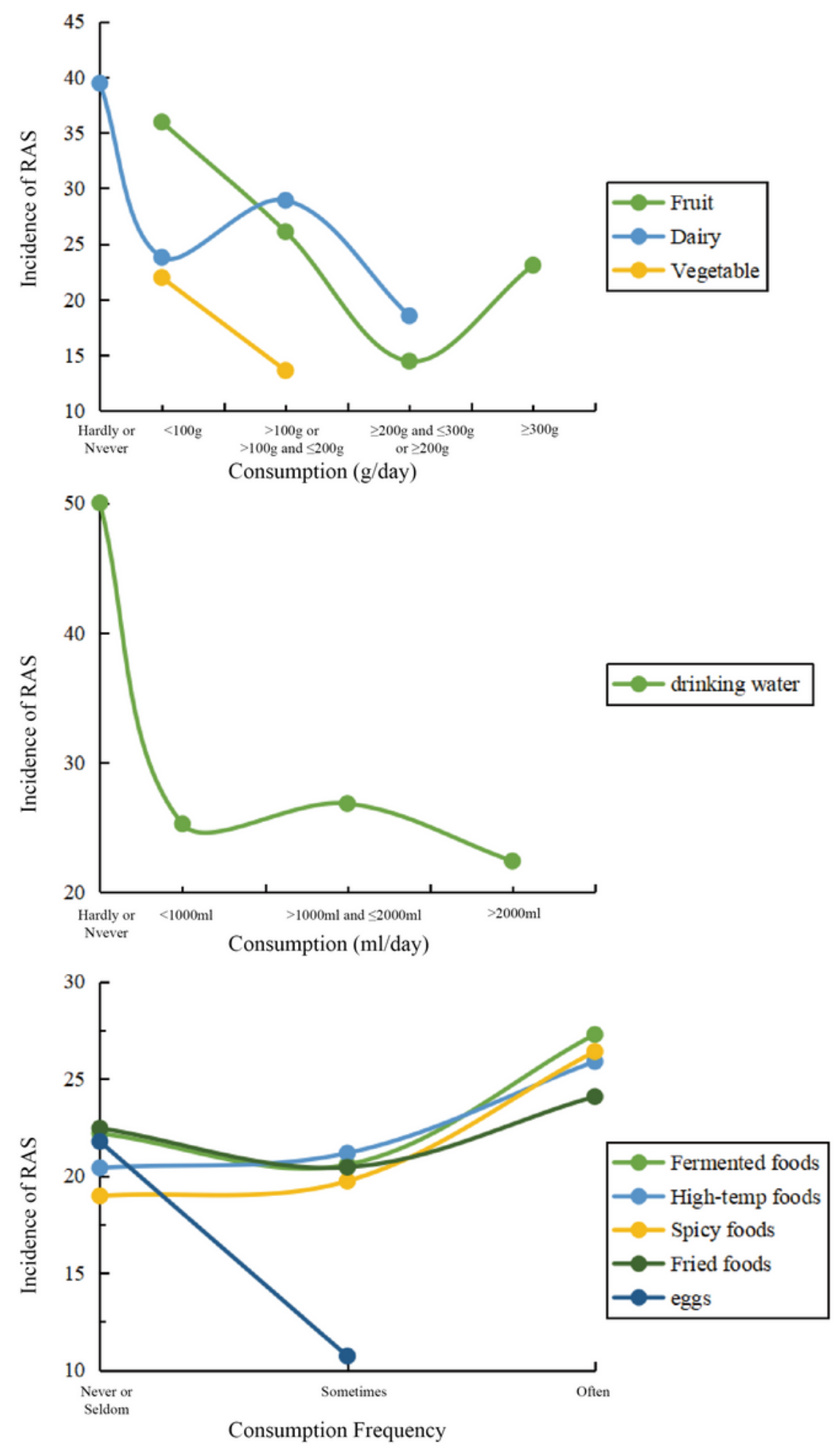

\section{Figure 2}

Distribution of the RAS rates in groups with different dietary habits, including fruits, dairy products, and vegetables (A), drinking water (B), and spicy foods, high-temp foods, fried foods, and fermented foods (C). 
Fruit

$\leqslant 100 \mathrm{~g}$

$>100 \mathrm{~g}$ and $\leqslant 200 \mathrm{~g}$

$>200 \mathrm{~g}$ and $\leqslant 300 \mathrm{~g}$

$>300 \mathrm{~g}$

Dairy

Hardly or never

$\leqslant 100 \mathrm{~g}$

$>100 \mathrm{~g}$ and $\leqslant 200 \mathrm{~g}$

$>200 \mathrm{~g}$

Drinking water

Hardly or never

$\leqslant 1000 \mathrm{ml}$

$>1000 \mathrm{ml}$ and $<2000 \mathrm{ml}$

$>2 \mathrm{~L}$

Vegetable

$\leqslant 100 \mathrm{~g}$

$>100 \mathrm{~g}$
Adjusted OR (95\% CI, $P$ Value)

$0.740(0.491-1.114,0.149)$

$0.430(0.218-0.847,0.015)$

$0.715(0.269-1.903,0.502)$

$0.716(0.403-1.269,0.252)$

$0.996(0.565-1.756,0.990)$

$0.632(0.294-1.358,0.240)$

$0.294(0.119-0.726,0.008)$

$0.343(0.140-0.843,0.020)$

$0.276(0.098-0.777,0.015)$

$0.683(0.412-1.131,0.138)$

Figure 3

Multivariable logistic regression of the relationship between dietary factors and RAS. aAdjusted for age and gender. 